\title{
Detection of Polycyclic Aromatic Hydrocarbons in Water Samples by Annular Platform-Supported Ionic Liquid-Based Headspace Liquid-Phase Microextraction
}

\author{
Xiaojie Sun $\mathbb{D}^{1},{ }^{1}$ Jie Tan $\mathbb{D}^{1},{ }^{1,2}$ Haiyan Ding $\mathbb{D}^{1},{ }^{1}$ Xiaojie Tan $\mathbb{D}^{\circ},{ }^{3}$ Jun Xing $\mathbb{D},{ }^{4}$ Lihong Xing, \\ Yuxiu Zhai, ${ }^{1}$ and Zhaoxin Li ${ }^{1}{ }^{1}$ \\ ${ }^{1}$ Key Laboratory of Testing and Evaluation for Aquatic Product Safety and Quality, Ministry of Agriculture and Rural Affairs, \\ Yellow Sea Fisheries Research Institute, Chinese Academy of Fishery Sciences, Qingdao 266071, China \\ ${ }^{2}$ Qingdao National Laboratory for Marine Science and Technology, Qingdao 266000, China \\ ${ }^{3}$ The Affiliated Hospital of Qingdao University, Qingdao 266000, China \\ ${ }^{4}$ Key Laboratory of Analytical Chemistry for Biology and Medicine, Ministry of Education, College of Chemistry and Molecular \\ Sciences, Wuhan University, Wuhan 430072, China \\ Correspondence should be addressed to Jie Tan; tanjie@ysfri.ac.cn and Zhaoxin Li; lizx@ysfri.ac.cn
}

Received 1 May 2018; Revised 3 July 2018; Accepted 27 August 2018; Published 27 September 2018

Academic Editor: Luca Campone

Copyright (c) 2018 Xiaojie Sun et al. This is an open access article distributed under the Creative Commons Attribution License, which permits unrestricted use, distribution, and reproduction in any medium, provided the original work is properly cited.

In this paper, a new method of annular platform-supported headspace liquid-phase microextraction (LPME) was designed using ionic liquid as an extraction solvent, wherein extraction stability and efficiency were improved by adding an annular platform inside the extraction bottle. The ionic liquid 1-silicyl-3-benzylimidazolehexafluorophosphate was first synthesized and proved to be an excellent extraction solvent. Coupled with liquid chromatography, the proposed method was employed to analysis of polycyclic aromatic hydrocarbons (PAHs) in water and optimized in aspects of extraction temperature, extraction solvent volume, extraction time, $\mathrm{pH}$, stirring rate, and salt effect of solution. The results indicated that this method showed good linearity $\left(R^{2}>0.995\right)$ within $0.5 \mu \mathrm{g} \cdot \mathrm{L}^{-1}$ to $1000 \mu \mathrm{g} \cdot \mathrm{L}^{-1}$ for PAHs. The method was more suitable for extraction of volatile PAHs, with recoveries from $65.0 \%$ to $102 \%$ and quantification limits from 0.01 to $0.05 \mu \mathrm{g} \cdot \mathrm{L}^{-1}$. It has been successfully applied for detection of PAHs in seawater samples.

\section{Introduction}

PAHs have been included in the environmental control legislation by many agencies, such as the US Environmental Protection Agency (EPA) [1] and the European Union. The maximum admissible concentration of naphthalene $\left(1200 \mathrm{ng} \cdot \mathrm{L}^{-1}\right), \quad$ anthracene $\left(100 \mathrm{ng} \cdot \mathrm{L}^{-1}\right), \quad$ fluoranthene $\left(100 \mathrm{ng} \cdot \mathrm{L}^{-1}\right)$, and benzo[a]pyrene $\left(100 \mathrm{ng} \cdot \mathrm{L}^{-1}\right)$ for superficial water was restricted by the European Union [2, 3]. To better evaluate the impact of PAHs on ecosystems, an efficient and sensitive analysis method must be developed. However, PAHs are found at very low levels (ng. $\mathrm{L}^{-1}$ or $\mathrm{pg} \cdot \mathrm{L}^{-1}$ ) in environment samples. It is necessary to perform an enrichment step in sample preparation due to the lack of sensitivity obtained with conventional analytical instrumentation.

Sample pretreatment has been the bottleneck of analytical chemistry. In recent decades, LPME has been developed rapidly as a novel pretreatment technology [4-7], reducing analysis time and large amounts of toxic solvent. Due to the low miscibility with water [8-10], ionic liquids (ILs) have become a new extraction solvent for LPME $[11,12]$ and been extensively applied in sample pretreatment prior to chromatography [13-24], overcoming the toxicity and reducing the consumption of ordinary organic solvents. In addition, characteristics of ILs can be tuned by a combination of different anions and cations for task-specific extraction of analytes in various solvent mediums. 
According to extraction patterns, application of ILs in the LPME technology can be classified into the following: dispersive liquid-liquid microextraction (DLLME) [25], hollow-fiber LPME [26], and suspended single-drop microextraction (SDME). Dispersive LPME requires large extraction amount with limited extraction efficiency; hollow-fiber LPME features low recovery with poor reproducibility; SDME has drawn much concern owing to its high enrichment efficiency. However, research studies showed that the sample solution should be stirred continuously during SDME, so extraction droplets easily fall off, affecting extraction stability and reproducibility. Furthermore, the droplets' volume of SDME was restricted, although adding a silicon rubber tube [12], a polytetrafluoroethylene sleeve [15], or a plastic tube [27] on a syringe needle seriously limits the improvement of extraction efficiency. Therefore, the SDME device and pattern should be optimized to promote the development of SDME technology. Furthermore, ILs have played crucial roles in the aspect. 1-Octyl-3-methylimidazolehexafluorophosphate $\left(\left[\mathrm{C}_{8} \mathrm{MIM}\right] \mathrm{PF}_{6}\right)$ was first used as an SDME solvent coupled with liquid chromatography to extract PAHs and aniline compounds in water samples [12]. Since then, some other types of ILs were used as an extraction solvent for SDME [28].

In this study, an IL-based headspace LPME device was designed using the homemade IL 1-silicyl-3benzylimidazolehexafluorophosphate $\left([\mathrm{SBnIM}] \mathrm{PF}_{6}\right)$ as an extraction solvent. The device was optimized by adding an annular platform inside the extraction bottle; then, IL was slowly pressed dropwise down to the annular platform by a syringe. The developed method was named "annular platform-supported IL-based headspace LPME" (APS-ILLPME). The method altered the suspension state of extracted droplets, overcame the influence of droplet gravity, and significantly improved extraction stability and efficiency. Meanwhile, the large extraction platform can flexibly regulate addition of extraction solvent to control extraction capacity and enrichment efficiency. Considering that fluoranthene and naphthalene showed larger partition coefficients in the system of $\left[\mathrm{C}_{n} \mathrm{MIM}\right]\left[\mathrm{PF}_{6}\right] /$ water $[9,29]$, liquid chromatography was combined with APS-IL-LPME to determine PAHs in water samples. Simultaneously, the IL $[\mathrm{SBnIM}] \mathrm{PF}_{6}$ containing the benzyl group in the structure of cation was used as an extraction solvent, which will be more suitable for extraction of analytes including benzene rings. The influence of different parameters on extraction was investigated and optimized in aspects of extraction temperature, extraction solvent volume, extraction time, $\mathrm{pH}$, stirring rate, and salt effect of solution. Moreover, the proposed method was compared with other preconcentration methods for determination of PAHs in water samples.

\section{Materials and Methods}

2.1. Apparatus and Reagents. A 2695 high-performance liquid chromatograph was equipped with an automatic sampler and a 2475 fluorescence detector (Waters Corp., US). An XW-80A vortex mixer (Shanghai Medical
University Instrument Factory), a Milli-Q ultrapure water meter (Millipore Corp., US), and a Sorvall Biofuge Primo centrifuge (Thermo Fisher Scientific Corp., US) were used.

1-Benzylimidazole (99\%) was purchased from Fluka Corp. (US). $\gamma$-Chloropropyl-trimethylsilane, naphthalene (99\%, Nap), acenaphthene (98\%, Acp), fluorene (98\%, Flu), anthracene (98.5\%, Ant), fluoranthene (98\%, FL), and pyrene (98\%, Pyr) were purchased from AccuStandard Corp. (US). Acetonitrile was purchased from Shanghai ANPEL Corp. (China). Other solvents and reagents were of analytical grade (SCRC, China). The water used in this experiment was redistilled. With a brown glass bottle, water samples were collected from seawater in Shazikou, Qingdao, Shandong Province, and preserved under $4^{\circ} \mathrm{C}$. Concentrations of six kinds of standard $\mathrm{PAH}$ stock solutions were separately $1.0 \mathrm{mg} \cdot \mathrm{mL}^{-1}$, which were dissolved in acetonitrile, and the mixed standard stock solution was diluted to $10.0 \mu \mathrm{g} \cdot \mathrm{mL}^{-1}$ by acetonitrile. Subsequently, the solutions were stored at $-20^{\circ} \mathrm{C}$ and diluted into standard working solutions of different concentrations by acetonitrile as needed.

2.2. The Device of APS-IL-LPME. The APS-IL-LPME device was self-manufactured in the lab. As shown in Figure 1, the whole device includes a thermostatic water bath ((2) in Figure 1), a heatable magnetic stirrer ((3) in Figure 1), and an extraction bottle with a sealing bottle cap ((1) in Figure 1). The thermostatic water bath is laid on the heatable magnetic stirrer, and the extraction bottle (made of glass) with a sealing bottle cap (made of polytetrafluoroethylene) is placed in the thermostatic water bath and fixed on an iron stand. The extraction bottle mainly consisted of the upper bottle body (ID $4.0 \mathrm{~cm}$, height $4.5 \mathrm{~cm}$; (5) in Figure 1), annular extraction platform (width $0.75 \mathrm{~cm}$; (7) in Figure 1), and lower bottle body (ID $2.5 \mathrm{~cm}$, height $4.0 \mathrm{~cm}$; (6) in Figure 1), all of which are integrated as a whole from top to bottom. Inner diameter of the upper bottle body is larger than that of the lower bottle body, and the annular extraction platform is a platform with high inner and outer sides and a sunken middle part, which is used to bear the weight of extracted droplets.

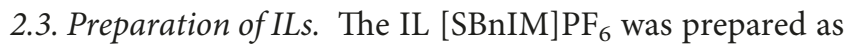
shown in Figure 2. Firstly, 1-benzylimidazolium was synthesized [30]. Then, [SBnIM]Cl (A) was prepared through a reaction between $\gamma$-chloropropyl-trimethylsilane and benzylimidazolium, which was according to the references $[31,32]$. Lastly, the chloride anion was exchanged for the hexafluorophosphate anion $\left(\mathrm{PF}_{6}{ }^{-}\right)[33]$.

The general procedures for the synthesis of 1-benzylimidazole were as follows: formaldehyde water solution $(36 \%, 8.35 \mathrm{~g})$ and glyoxal water solution $(32 \%, 18.1 \mathrm{~g})$ were added to a $250 \mathrm{~mL}$, three-necked flask provided with a stirrer and a reflux condenser. While the mixture was heated to $50^{\circ} \mathrm{C}$, a mixture of benzylamine solution $(10.7 \mathrm{~g}$ in $50 \mathrm{~mL}$ methanol) and ammonia solution $(28 \%, 6.05 \mathrm{~g})$ was added dropwise. After the mixture refluxed for an additional $4 \mathrm{~h}$ at $50^{\circ} \mathrm{C}$, the methanol and water were removed under reduced 


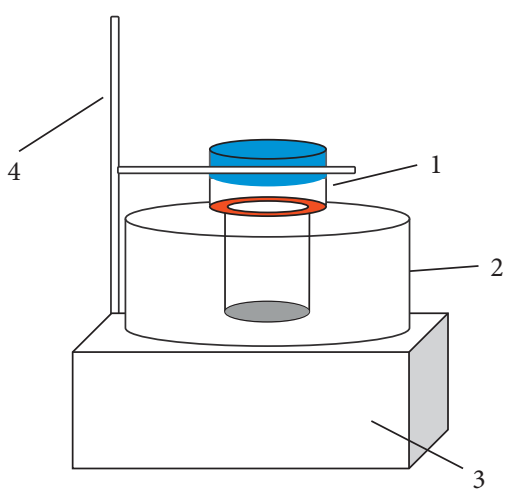

(a)

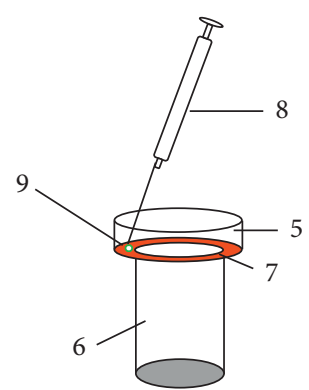

(b)

Figure 1: The device for APS-IL-LPME. (a) (1) Extraction bottle; (2) thermostatic water bath; (3) heating magnetic stirrer; (4) iron stand. (b)

(5) The upper bottle; (6) the lower bottle; (7) annular extraction platform; (8) microsyringe; (9) ionic liquid droplets.

$\mathrm{PhCH}_{2} \mathrm{NH}_{2}+\mathrm{NH}_{3}+\mathrm{OHC}-\mathrm{CHO}+\mathrm{HCHO} \longrightarrow \stackrel{=}{\longrightarrow} \frown$<smiles></smiles>

(a)
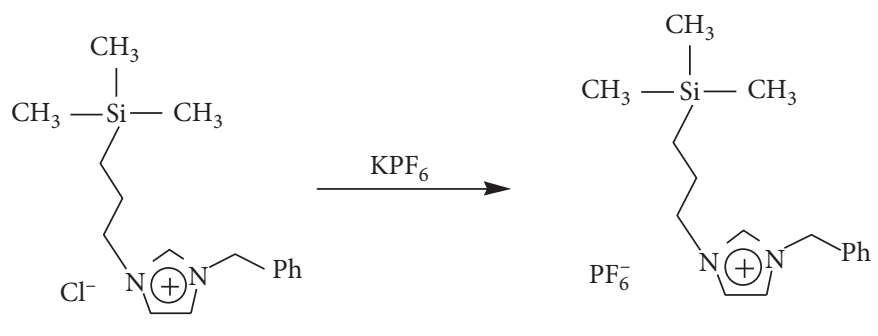

(3)

(b)

FIgURE 2: Synthetic routes of the ionic liquid $\left[\mathrm{SBnIM}_{\mathrm{P}} \mathrm{PF}_{6}\right.$.

pressure. The residue was then concentrated and dried in a vacuum desiccator at $60^{\circ} \mathrm{C}$. The product of 1-benzylimidazole was obtained with the yield about $75 \%$.

Secondly, 1-benzylimidazole $(0.05 \mathrm{~mol}, 4.60 \mathrm{~g})$ was added dropwise to a solution of $\gamma$-chloropropyltrimethylsilane $(0.05 \mathrm{~mol}, 17.3 \mathrm{~g}$ in $25 \mathrm{~mL}$ toluene). The solution was then refluxed for $72 \mathrm{~h}$ under $\mathrm{N}_{2}$ atmosphere. The resultant was washed with deionized water to remove the residue of reactants. After concentrating and drying, the light-yellow transparent and viscous compound [SBnIM] Cl (A) was obtained and the yield was about $90 \%$.

Then, the IL $\left[\mathrm{SBnIM}_{\mathrm{P}} \mathrm{PF}_{6}\right.$ (B) was prepared through anion-exchange reactions. The process was as follows: the compound [SBnIM]Cl (A) was dissolved in water, and then $1 \mathrm{M}$ equivalent of $\mathrm{KPF}_{6}$ in water was added dropwise. After stirring for $24 \mathrm{~h}$ at room temperature, the resultant was dissolved in dichloromethane and washed with deionized water. The silver nitrate test was used to confirm absence of chloride. Finally, the product was concentrated and dried, forming a light-yellow viscous compound $\left[\mathrm{SBnIM} \mathrm{PF}_{6}(\mathrm{~B})\right.$, and the yield reached $90 \%$.

The final product $[\mathrm{SBnIM}] \mathrm{PF}_{6}$ was confirmed by proton nuclear magnetic resonance $\left({ }^{1} \mathrm{HNMR}\right)$ spectroscopy and Fourier transform infrared (FT-IR) spectroscopy. (i) ${ }^{1} \mathrm{HNMR}\left(\mathrm{D}_{2} \mathrm{O} ; 400 \mathrm{MHz} ; \delta(\mathrm{ppm})\right): 8.76(\mathrm{~s}, 1 \mathrm{H}), 7.42-7.43$ $(\mathrm{d}, 2 \mathrm{H}), 7.33-7.41(\mathrm{~m}, 5 \mathrm{H}), 5.28(\mathrm{~s}, 2 \mathrm{H}), 4.09(\mathrm{t}, 2 \mathrm{H}), 3.44(\mathrm{~m}$, 9H), $1.83(\mathrm{~m}, 2 \mathrm{H})$, and $0.56(\mathrm{~m}, 2 \mathrm{H})$. (ii) FT-IR (KBr, $v$ $\left.\left(\mathrm{cm}^{-1}\right)\right): 3127$ and $3059[v(\mathrm{Ar}-\mathrm{H})] ; 2958,2932$, and 2868 $[v(\mathrm{C}-\mathrm{H})] ; 1558,1494$, and $1452[v(\mathrm{C}=\mathrm{C}), v(\mathrm{C}=\mathrm{N})] ; 1156$ $[v(\mathrm{Si}-\mathrm{C})] ; 1083$ and $1023[v(\mathrm{Si}-\mathrm{O})]$; and $836[v(\mathrm{P}-\mathrm{F})]$. 
2.4. Extraction Procedures. First, $10 \mathrm{~mL}$ of the PAH-spiked water sample $\left(5.0 \mu \mathrm{g} \cdot \mathrm{L}^{-1}\right)$ was transferred to the extraction bottle, and sodium chloride was added to saturated concentration. The solution was inside the lower bottle body and remained below the annular extraction platform, which was headspace LPME. The sealing bottle cap was opened; the front end of the microsyringe $(100 \mu \mathrm{L})$ was placed in the middle position of the annular extraction platform (as shown in Figure 1(b)). Then, the syringe was slowly pressed down to release ILs $(50 \mu \mathrm{L})$ on the annular platform. The sealing bottle cap was fastened down; extraction was then implemented through stirring with the required water bath temperature. After extraction, the sealing bottle cap was loosened, the microsyringe was directly used to absorb IL on the annular platform, the solution was diluted to $100 \mu \mathrm{L}$ using acetonitrile, and $10 \mu \mathrm{L}$ of the solution was absorbed through the automatic sampler for high-performance liquid chromatography (HPLC) analysis.

2.5. Analysis Conditions. The analytes were separated on a Waters $\mathrm{PAHC}_{18}$ chromatographic column $(250 \mathrm{~mm} \times 4.6 \mathrm{~mm}$, ID $5 \mu \mathrm{m}$, Waters Corp.) at a column temperature of $40^{\circ} \mathrm{C}$. The sample injection volume was $10 \mu \mathrm{L}$. The mobile phase consisted of acetonitrile (A) and water (B). The total run time was $20.0 \mathrm{~min}$ with a flow rate of $1.0 \mathrm{~mL} \mathrm{~min}^{-1}$. The gradient elution steps were as follows: $0-10.0 \mathrm{~min}, \mathrm{~A}$ increased from $60 \%$ to $100 \%$, then remained at $100 \%$ until $16.0 \mathrm{~min}$, and thereafter returned to $60 \%$ in $1.0 \mathrm{~min}$, followed by reequilibration time for $3.0 \mathrm{~min}$. The parameters of emission wavelength $\left(\lambda_{\mathrm{em}}\right)$ and excitation wavelength $\left(\lambda_{\mathrm{ex}}\right)$ for PAHs on a fluorescence detector are shown in Table 1.

\section{Results and Discussion}

3.1. Optimization of Extraction Conditions. Extraction efficiency of ILs for the analytes was mainly influenced by several parameters. In this study, optimized parameters included volume of the extraction solvent, extraction temperature, extraction time, $\mathrm{pH}$, stirring rate, and salt effect of solution. During optimization of parameters, the PAHspiked water sample $\left(5.0 \mu \mathrm{g} \cdot \mathrm{L}^{-1}\right)$ was used as an extraction substrate. Extraction efficiencies of methods were evaluated through enrichment factors (EFs) and recoveries. Computational formulas were expressed as follows:

$$
\begin{aligned}
\mathrm{EFs} & =\frac{C_{t}}{C_{0}}=\frac{\left(n_{t} / v_{t}\right)}{C_{0}}, \\
\text { recovery } & =\left(\mathrm{EFs} \times \frac{V_{t}}{V_{0}}\right) \times 100 \%,
\end{aligned}
$$

where $C_{t}$ and $n_{t}$ refer to the concentration and molar quantity of PAHs in the extraction phase, respectively; $C_{0}$ is the initial concentration of PAHs in the water sample before extraction; $V_{t}$ corresponds to the final volume of the extraction phase; and $V_{0}$ stands for the volume of the water sample before extraction.

3.2. Volume of ILs. Volume of the extraction solvent is an important factor influencing extraction efficiency. This study
TABle 1: The fluorescence detection wavelengths for PAHs.

\begin{tabular}{lcc}
\hline Time $(\min )$ & $\lambda_{\mathrm{ex}}(\mathrm{nm})$ & $\lambda_{\mathrm{em}}(\mathrm{nm})$ \\
\hline 0 & 275 & 325 \\
6.85 & 252 & 370 \\
7.80 & 250 & 390 \\
9.00 & 280 & 460 \\
10.0 & 320 & 380 \\
11.5 & 270 & 390 \\
\hline
\end{tabular}

assessed influences of different volumes (10, 20, 50, 80, and $100 \mu \mathrm{L})$ of the IL [SBnIM] $\mathrm{PF}_{6}$ on extraction efficiency of six kinds of PAHs (Figure 3). When volume of IL was within $10 \mu \mathrm{L}$ to $50 \mu \mathrm{L}$, extraction efficiency gradually improved as volume enlarged; enrichment efficiency remained within $50 \mu \mathrm{L}$ to $80 \mu \mathrm{L}$ but decreased when IL volume increased to $100 \mu \mathrm{L}$. Thus, as volume of the extraction solvent enlarged, extraction amount $\left(n_{t}\right.$ in Formula $\left.(1)\right)$ of analytes correspondingly increased. However, when volume $\left(V_{t}\right)$ of the extraction solvent escalated too rapidly, analyte concentration $\left(C_{t}\right)$ and EFs decreased. Therefore, to obtain maximum enrichment efficiency and good reproducibility, volume of the IL extraction solvent was set at $50 \mu \mathrm{L}$.

3.3. Extraction Temperature. To obtain satisfactory enrichment efficiency, the added water sample should not be higher than the level of the annular extraction platform. The extraction process involved headspace LPME. Extraction temperature directly influenced velocity and concentration of analytes released from the water sample and then influenced extraction efficiency indirectly. The increase in extraction temperature will shorten equilibrium time, accelerate analysis, and increase concentration of analytes in the gas phase. However, extraction for analytes was an absorption process. Thus, high temperature will reduce the distribution coefficient of analytes in the extraction solvent and also diminish extraction amount. Therefore, this study also assessed influences of different temperatures on extraction efficiency (Figure 4). When the temperature increased from room temperature to $50^{\circ} \mathrm{C}$, EFs of six kinds of PAHs increased rapidly but slowed down under $50^{\circ} \mathrm{C}$ to $60^{\circ} \mathrm{C}$ and decreased under $70^{\circ} \mathrm{C}$. Thus, in this study, $50^{\circ} \mathrm{C}$ was selected as an optimal extraction temperature.

3.4. Extraction Time. Theoretically, before reaching the equilibrium during extraction, prolonged duration will increase contents of analytes absorbed by the extraction solvent. This study also evaluated the influence of extraction time on extraction efficiency under $50^{\circ} \mathrm{C}$ (Figure 5). EFs of different kinds of PAHs improved rapidly before $30 \mathrm{~min}$ and improved slowly afterward. In this study, the extraction time was set to $30 \mathrm{~min}$ to guarantee EFs of analytes. However, according to Figure 5, if larger EFs are desired, an extraction time up to $50 \mathrm{~min}$ would be adopted.

3.5. $\mathrm{pH}$ of Solution. To study the influence of $\mathrm{pH}$ on extraction efficiency, $1 \mathrm{~mol} \cdot \mathrm{L}^{-1} \mathrm{HCl}$ or $\mathrm{NaOH}$ was used to regulate $\mathrm{pH}$ of the extracted water sample within 2 to 13 . The 


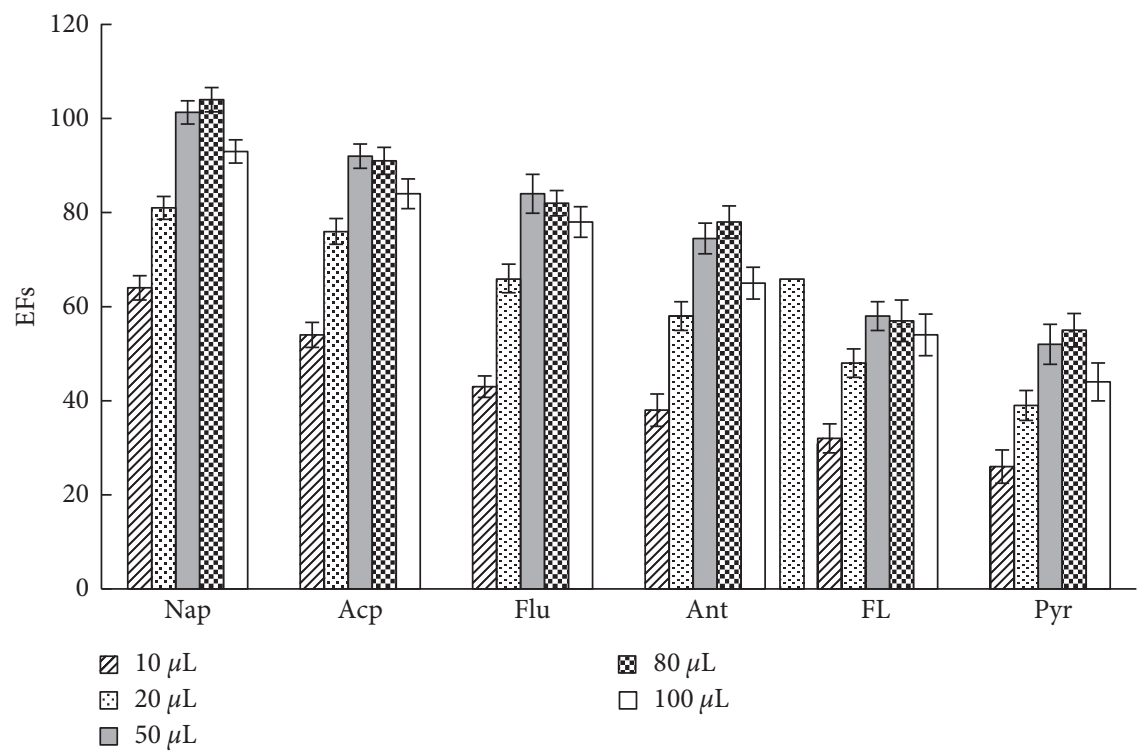

Figure 3: The effect of IL volume on EFs. Other extraction conditions: $10 \mathrm{~mL}$ of aqueous standards (containing PAHs at a concentration of $\left.5 \mu \mathrm{g} \cdot \mathrm{L}^{-1}\right)$; extraction temperature, $50^{\circ} \mathrm{C}$; extraction time, $30 \mathrm{~min}$; the concentration of $\mathrm{NaCl}, 25 \%$. Values are mean of $n=3$ replicates.

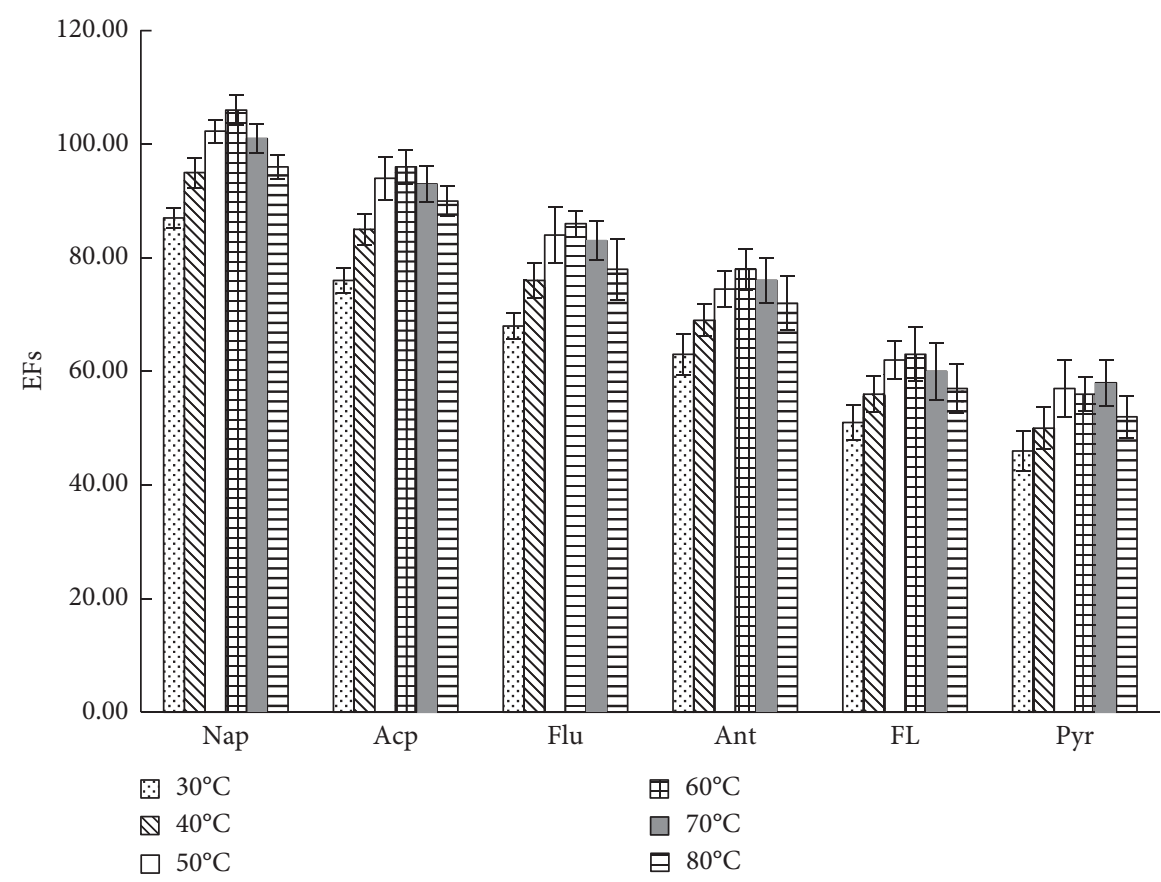

FIGURE 4: The effect of temperature on EFs. Other extraction conditions: $10 \mathrm{~mL}$ of aqueous standards (containing PAHs at a concentration of $\left.5 \mu \mathrm{g} \cdot \mathrm{L}^{-1}\right)$; extraction temperature, $50^{\circ} \mathrm{C}$; extraction solvent volume, $50 \mu \mathrm{L}$; extraction time, $30 \mathrm{~min}$; the concentration of $\mathrm{NaCl}, 25 \%$. Values are mean of $n=3$ replicates.

results indicated that $\mathrm{pH}$ exerted minor influence on extraction efficiency of PAHs. Maybe, it was due to the fact that PAHs had no ionizable groups and they were stable at the molecular state, a condition not influenced by $\mathrm{pH}$ of the solution. Therefore, for convenience and reproducibility, water samples can be directly extracted and enriched without any assistance only if their $\mathrm{pH}$ were within 2 to 13 .
3.6. Stirring Rate. In order to evaluate the influence of stirring rate, $10 \mathrm{~mL}$ of $5 \mu \mathrm{g} \cdot \mathrm{L}^{-1} \mathrm{PAH}$ mixed aqueous solution was extracted at $50^{\circ} \mathrm{C}$ for $30 \mathrm{~min}$ using $50 \mu \mathrm{L}$ [SBnIM] $\mathrm{PF}_{6}$ with stirring rates from 200 to $1500 \mathrm{rpm}$. Theoretically, before reaching the equilibrium, accelerating the stirring rate will increase contents of analytes absorbed by the extraction solvent. The results showed that extraction efficiency of all 


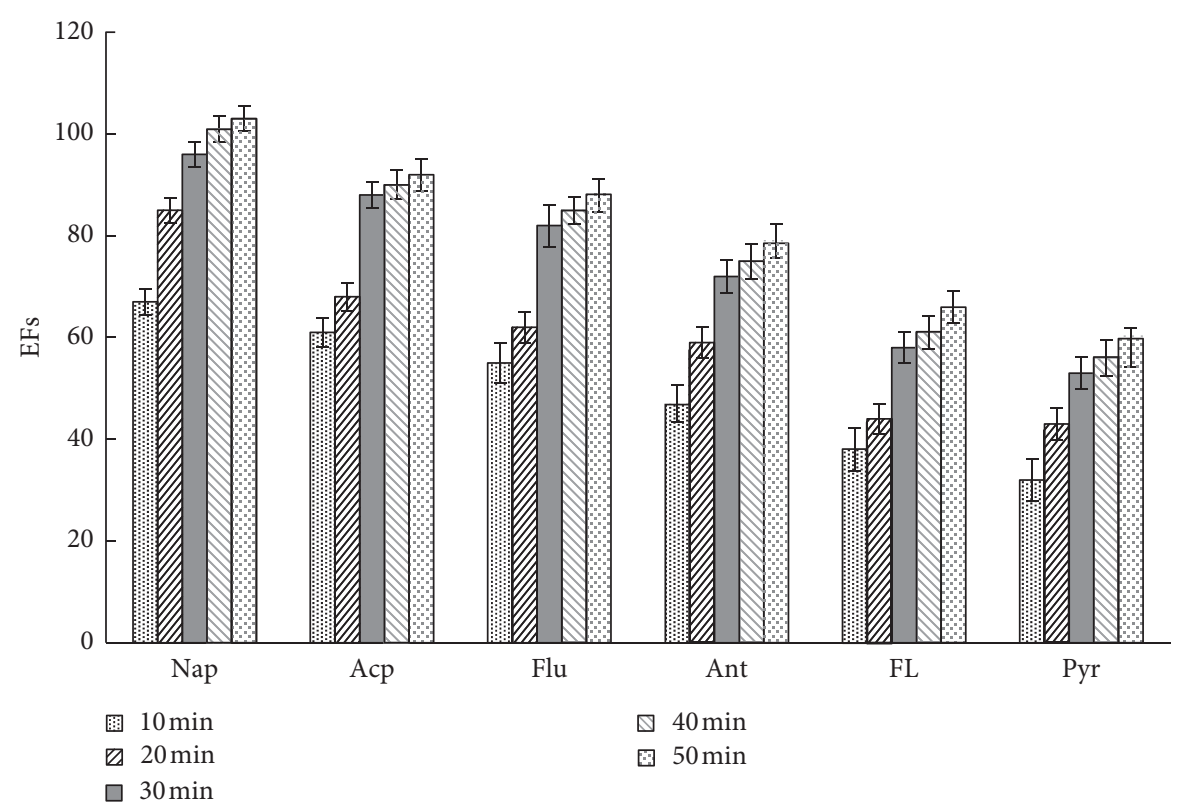

Figure 5: The effect of extraction time on EFs. Other extraction conditions: $10 \mathrm{~mL}$ of aqueous standards (containing PAHs at a concentration of $\left.5 \mu \mathrm{g} \cdot \mathrm{L}^{-1}\right)$; extraction temperature, $50^{\circ} \mathrm{C}$; extraction solvent volume, $50 \mu \mathrm{L}$; extraction time, $30 \mathrm{~min}$; the concentration of $\mathrm{NaCl}$, $25 \%$. Values are mean of $n=3$ replicates.

analytes slightly increased as the increase of stirring rate was up to $1000 \mathrm{rpm}$, while the reproducibility was poor after the stirring rate greater than $1000 \mathrm{rpm}$. A stirring rate of $1000 \mathrm{rpm}$ was selected in this work.

3.7. Salt Effect. In headspace LPME, adding $\mathrm{NaCl}$ in the sample solution can reduce solubility of analytes in the water phase, improve the gas-liquid partition coefficient, and enlarge concentration of analytes in the gas phase to increase extraction amount indirectly. However, extremely high $\mathrm{NaCl}$ concentration will hinder transport of analytes in the sample solution and influence their diffusion in the gas phase. This study assessed the effects of $\mathrm{NaCl}$ addition $(0 \%-36 \%, w / v)$ on extraction efficiency (Figure 6). The results showed that enrichment efficiency was the highest when the $\mathrm{NaCl}$ solution was saturated, indicating that reducing solubility of PAHs in the water phase exerted a significant influence. Therefore, the optimum concentration for salt addition was saturated $\mathrm{NaCl}$ solution.

3.8. MethodEvaluation. To evaluate practical applicability of the APS-IL-LPME method, reproducibility, limit of detection (LOD), and limit of quantification (LOQ) were investigated with $\mathrm{PAH}$-spiked ultrapure water under the optimum conditions, the results of which are summarized in Table 2. It showed that the method presented good linearity $\left(R^{2}>0.995\right)$ within $0.5 \mu \mathrm{g} \cdot \mathrm{L}^{-1}$ to $1000 \mu \mathrm{g} \cdot \mathrm{L}^{-1}$ for the six kinds of PAHs. Replicate extractions of spiked ultrapure water solution $\left(5.0 \mu \mathrm{g} \cdot \mathrm{L}^{-1}\right)$ were carried out on intraday and interday to show precision of the method. The relative standard deviation (RSD) of PAHs ranged from $4.7 \%$ to $11.6 \%$ in all cases, and LOQ was within $0.01 \mu \mathrm{g} \cdot \mathrm{L}^{-1}$ to $0.05 \mu \mathrm{g} \cdot \mathrm{L}^{-1}$. The recoveries of Nap, Acp, Flu, Ant, and FL were within $70.2 \%$ to $102 \%$, whereas only that of Pyr was lower than 70\%. Meanwhile, EFs ranged from 65.0 to 102 , which were comparable with those reported by Liu et al. [12].

The comparison of different methods for determination of PAHs in water is shown in Table 3. LLE [34] used less extraction time and exhibited low LOQ, but it was relatively solvent-consuming and had lower extraction efficiency. The SPE [35] method gave higher extraction efficiency. However, it exhibited high LOQ and needed more sample volume, while the operation of SPME [36] was complex and timeconsuming. The LPME combined with gas chromatography $[25,37,38]$ showed higher LOQs. The IL-SDME method [12] showed high EFs, while had lower extraction efficiency $(<50 \%)$, calculated according to Formula (2) in Section 3.1. The previous reported IL-LPME methods [12, 22, 39, 40] all used $\left[\mathrm{C}_{8} \mathrm{MIM}\right] \mathrm{PF}_{6}$ as an extraction solvent, and the LODs of most of them were higher than those of the proposed method. In conclusion, the proposed APS-IL-LPME method is simple, stable, and an advantageous alternative, the extraction efficiency and LOQ of which are better than or comparable with those of other methods.

3.9. Application to Real Water Samples. Seawater samples collected from Shazikou in Qingdao and corresponding PAH-spiked seawater samples were extracted and detected according to the optimization method. As shown in Figure 7(c), no PAHs were found in the seawater sample. To evaluate this method, the seawater sample was spiked with PAHs at two levels (5.0 and $\left.10 \mu \mathrm{g} \cdot \mathrm{L}^{-1}\right)$. As can be seen in Table 4 , the recoveries for six PAHs were from $67.2 \%$ to $106 \%$ with the RSD between $3.5 \%$ and $10.4 \%$. Compared with the recoveries of PAHs in spiked ultrapure water solution, the effects of matrix constituents were minor. 


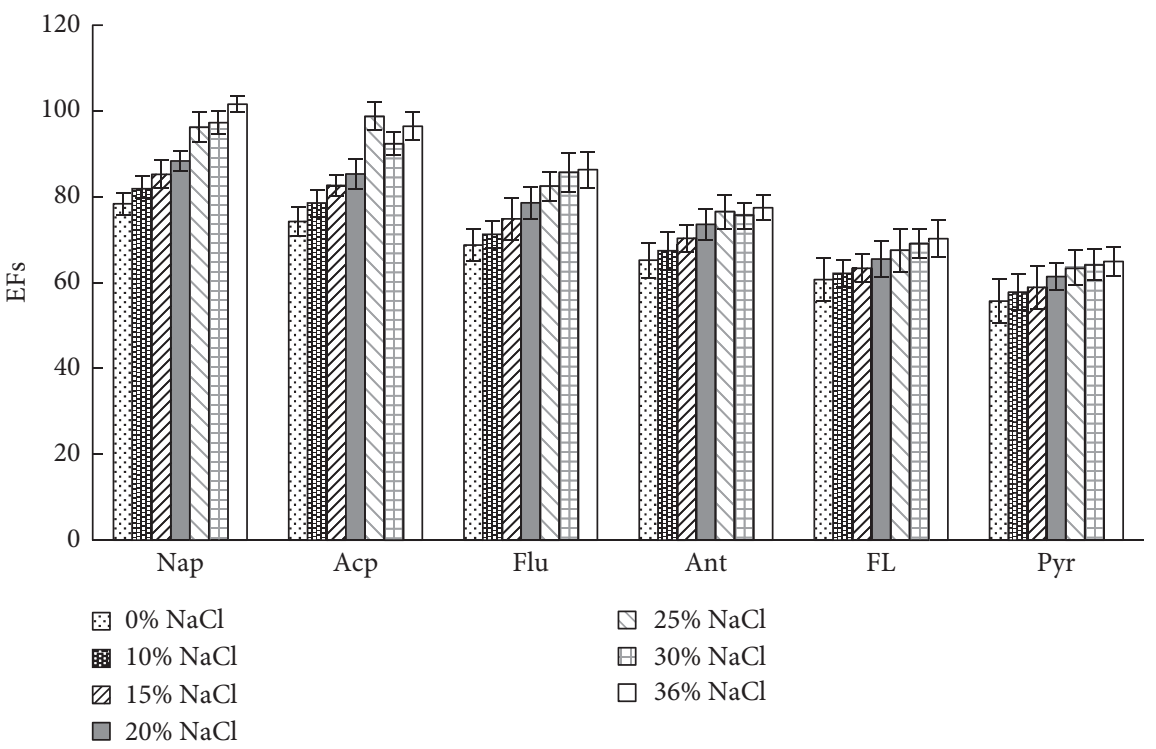

Figure 6: The effect of $\mathrm{NaCl} \%$ on EFs. Other extraction conditions: $10 \mathrm{~mL}$ of aqueous standards (containing PAHs at a concentration of $5 \mu \mathrm{g} \cdot \mathrm{L}^{-1}$ ); extraction temperature, $50^{\circ} \mathrm{C}$; extraction solvent volume, $50 \mu \mathrm{L}$; extraction time, $30 \mathrm{~min}$. Values are mean of $n=3$ replicates.

TABLE 2: Main analytical parameters for the enrichment of PAHs with the proposed method.

\begin{tabular}{|c|c|c|c|c|c|c|}
\hline \multirow{2}{*}{ Analytes } & \multirow{2}{*}{ Linear range $\left(\mu \mathrm{g} \cdot \mathrm{L}^{-1}\right)$} & \multirow{2}{*}{$R^{2}$} & \multirow{2}{*}{ LODs $\left(\mu \mathrm{g} \cdot \mathrm{L}^{-1}\right)$} & \multirow{2}{*}{ LOQs $\left(\mu \mathrm{g} \cdot \mathrm{L}^{-1}\right)$} & \multicolumn{2}{|c|}{ Precision (\%RSD) } \\
\hline & & & & & Intraday $(n=6)$ & Interday $(n=3)$ \\
\hline Nap & $0.5-1000$ & 0.9981 & 0.003 & 0.01 & 4.7 & 7.9 \\
\hline Acp & $0.5-1000$ & 0.9976 & 0.003 & 0.01 & 4.8 & 7.4 \\
\hline Flu & $0.5-1000$ & 0.9954 & 0.006 & 0.02 & 5.1 & 8.1 \\
\hline Ant & $0.5-1000$ & 0.9988 & 0.010 & 0.03 & 5.5 & 10.7 \\
\hline FL & $0.5-1000$ & 0.9963 & 0.015 & 0.05 & 6.8 & 11.6 \\
\hline Pyr & $0.5-1000$ & 0.9972 & 0.003 & 0.01 & 5.3 & 9.6 \\
\hline
\end{tabular}

TABLE 3: Comparison of the proposed method with other preconcentration methods for determination of PAHs in water.

\begin{tabular}{|c|c|c|c|c|c|c|c|c|}
\hline $\begin{array}{l}\text { Preconcentration } \\
\text { technique }\end{array}$ & $\begin{array}{l}\text { Analytical } \\
\text { technique }\end{array}$ & $\begin{array}{l}\text { Extraction } \\
\text { solvent }\end{array}$ & $\begin{array}{c}\text { Sample } \\
\text { volume } \\
(\mathrm{mL})\end{array}$ & $\begin{array}{c}\text { Solvent } \\
\text { volumea } \\
(\mathrm{mL})\end{array}$ & $\begin{array}{l}\text { Extraction } \\
\text { time (min) }\end{array}$ & $\begin{array}{c}\text { Extraction } \\
\text { efficiency (\%) }\end{array}$ & $\operatorname{LOQ}\left(\mu \mathrm{g} \cdot \mathrm{L}^{-1}\right)$ & Reference \\
\hline LLE & HPLC-Flu & $\mathrm{CH}_{2} \mathrm{Cl}_{2}$ & 250 & 90 & 6 & $51-104$ & $0.1-4.4$ & {$[34]$} \\
\hline SPE & HPLC-Flu & $\mathrm{C}_{6} \mathrm{H}_{14}-\mathrm{CH}_{2} \mathrm{Cl}_{2}$ & 50 & 5 & 50 & $67-99$ & $0.7-56.2$ & [35] \\
\hline SPME & $\begin{array}{c}\text { GC- } \\
\mathrm{MS} / \mathrm{MS}\end{array}$ & - & 18 & - & 70 & $60-102$ & $0.1-1.0$ & {$[36]$} \\
\hline DLLME & GC-FID & $\mathrm{C}_{2} \mathrm{Cl}_{4}$ & 5 & 0.008 & Seconds & $60-111$ & $23.3-100.0$ & {$[25]$} \\
\hline LLME-FA & GC-FID & Toluene & 22 & 0.05 & 5 & $100-108$ & 14-41 (LOD) & {$[37]$} \\
\hline IL-DLLME & GC-MS & $\begin{array}{l}{\left[\mathrm{P}_{\left.6,6,6,14^{+}\right][\mathrm{Ni}}\right.} \\
(\mathrm{II})\left(\text { hfacac }_{3}{ }^{-}\right]\end{array}$ & 25 & 0.025 & 10 & $84-115$ & $0.5-8.7$ (LOD) & {$[38]$} \\
\hline IL-DLLME & HPLC-UV & {$\left[\mathrm{C}_{8} \mathrm{MIM}\right] \mathrm{PF}_{6}$} & 10 & 0.055 & 30 & $83.5-118$ & $0.0005-0.88(\mathrm{LOD})$ & [39] \\
\hline IL-DLLME & HPLC-Flu & {$\left[\mathrm{C}_{8} \mathrm{MIM}\right] \mathrm{PF}_{6}$} & 10 & 0.05 & 2 & $90-102$ & $0.1-7.0$ & {$[22]$} \\
\hline IL-SDME & HPLC-Flu & {$\left[\mathrm{C}_{8} \mathrm{MIM}\right] \mathrm{PF}_{6}$} & 15 & 0.003 & 30 & - & - & {$[12]$} \\
\hline IL-HS-LPME & HPLC-Flu & {$\left[\mathrm{C}_{8} \mathrm{MIM}\right] \mathrm{PF}_{6}$} & 5 & 0.003 & 60 & $88-110$ & $\begin{array}{c}0.03-0.1 \text { (LOD) } \\
0.01-0.05\end{array}$ & {$[40]$} \\
\hline APS-IL-LPME & HPLC-Flu & {$[\mathrm{SBnIM}] \mathrm{PF}_{6}$} & 10 & 0.05 & 30 & $65.0-102$ & $\begin{array}{c}(\mathrm{LOQ}) / 0.003-0.015 \\
(\mathrm{LOD})\end{array}$ & This work \\
\hline
\end{tabular}

-, not required or not available. ${ }^{\text {T}}$ The volume of extraction solvent needed in the extraction process.

Figure $7(\mathrm{~b})$ shows the typical chromatogram of the sample spiking with $10 \mu \mathrm{g} \cdot \mathrm{L}^{-1}$ of the PAHs. After APS-ILLPME, PAHs in seawater were enriched effectively, and the baseline was well separated. Combined with the results from
Figures 3-6 and Table 4, EFs and recoveries decreased gradually with increasing boiling point and molecular weight due to decreased molecule diffusion and gas-liquid partition coefficient. The results were consistent with the 


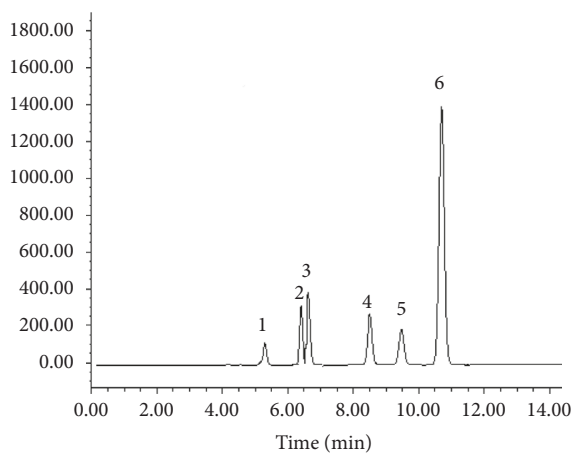

(a)

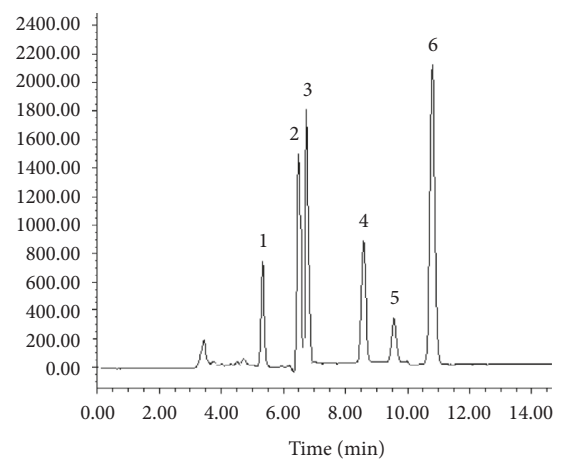

(b)

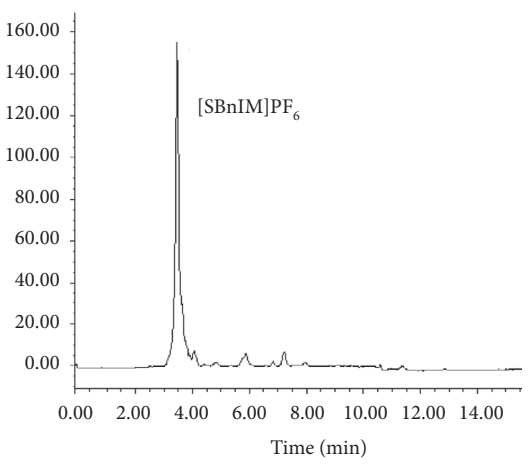

(c)

Figure 7: Chromatograms of (a) standard solution $\left(200 \mu \mathrm{g} \cdot \mathrm{L}^{-1}\right)$, (b) ionic liquid extracted spiked seawater (10 $\left.\mu \mathrm{g} \cdot \mathrm{L}^{-1}\right)$, and (c) ionic liquidextracted blank seawater. Peaks: (1) naphthalene; (2) acenaphthene; (3) fluorene; (4) anthracene; (5) fluoranthene; (6) pyrene.

TABLE 4: Spiked recoveries of the six PAHs in real seawater samples.

\begin{tabular}{lccc}
\hline Analytes & Spiked amounts $\left(\mu \mathrm{g} \cdot \mathrm{L}^{-1}\right)$ & Average recovery $(\%)$ & RSD $(\%)(n=5)$ \\
\hline \multirow{2}{*}{ Nap } & 5 & 106 & 4.2 \\
& 10 & 105 & 3.5 \\
Acp & 5 & 97.8 & 5.5 \\
& 10 & 95.3 & 7.5 \\
Flu & 5 & 86.2 & 9.7 \\
& 10 & 81.4 & 6.1 \\
Ant & 5 & 77.3 & 6.3 \\
& 10 & 79.8 & 6.0 \\
FL & 5 & 72.5 & 6.5 \\
& 10 & 70.3 & 4.9 \\
Pyr & 5 & 68.3 & 10.4 \\
\end{tabular}

findings of headspace LPME reported by other studies [12], indicating that this method is more suitable for enrichment of volatile PAHs in water samples due to the nonvolatile property of IL.

\section{Conclusions}

This work proposed a new method of APS-IL-LPME using the IL $[\mathrm{SBnIM}] \mathrm{PF}_{6}$ as an extraction solvent, which overcame the influence of IL gravity and significantly improved extraction stability and efficiency. The IL [SBnIM] $\mathrm{PF}_{6}$ was homemade and proved to be an excellent extraction solvent for LPME. Combined with liquid chromatography, the method was employed to detect PAHs in the water sample. The optimized conditions for extraction were under $50^{\circ} \mathrm{C}$ for 30 min with $50 \mu \mathrm{L}$ extraction solvent and saturated $\mathrm{NaCl}$ concentration in the sample solution. The results indicated that the extraction efficiency and LOQ of the method were better than or comparable with the previously reported ones and suitable for detection of PAHs, such as Nap, Acp, Flu, Ant, FL, and Pyr, in water solutions, with EFs ranging from 65.0 to 102 and LOQ from 0.01 to $0.05 \mu \mathrm{g} \cdot \mathrm{L}^{-1}$. The APS-ILLPME method was first used for enrichment of PAHs in real seawater samples, indicating that it will have broad potential in enrichment and analysis of organic pollutants in the environment and food samples. This method is especially advantageous for the enrichment of volatile compounds and shows higher extraction stability than suspended SDME by adding an annular platform. However, as the headspace LPME mode, the amount of water samples is limited and not higher than the level of annular platform. Moreover, in this work, nonvolatile compounds are not transferred to the headspace and not extracted by the ionic liquids. In the future work, we will continue to develop a new extraction mode to apply this method in immersed LPME for extraction of nonvolatile compounds.

\section{Data Availability}

The data used to support the findings of this study are included within the article.

\section{Conflicts of Interest}

The authors declare that they have no financial and commercial conflicts of interest in connection with the work submitted.

\section{Acknowledgments}

This work was kindly supported by the Special Scientific Research Funds for Central Non-Profit Institutes, Yellow Sea Fisheries Research Institute, Chinese Academy of Fishery Sciences (No. 20603022016007), National Key R\&D 
Program of China (No. 2017YFC1600705), National Natural Science Foundation of China (No. 21207162), and Key Laboratory of Separation Sciences for Analytical Chemistry, Dalian Institute of Chemical Physics, Chinese Academy of Sciences (No. KL-1604).

\section{References}

[1] United States Environmental Protection Agency, National Primary Drinking Water Standards, United States Environmental Protection Agency, Washington, DC, USA, 2003.

[2] European Commission, Directive 2006/0129 of the European Parliament and of the Council on Environmental Quality Standards in the Field of Water Policy and Amending Directive 2000/60/EC, European Commission, Brussels, Belgium, 2006.

[3] European Commission, Directive 2008/105/EC, 2008, Official Journal of the European Communities L-348/84 (24th December, 2008), Council Directive (16th December, 2008) on Environmental Quality Standards in the Field of Water Policy, Amending and Subsequently Repealing Council Directives 82/ 176/EEC, 83/513/EEC, 84/156/EEC, 84/491/EEC, 86/280/EEC and Amending Directive 2000/60/EC of the European Parliament and of the Council, European Commission, Brussels, Belgium, 2008.

[4] D. Nagaraju and S. D. Huang, "Determination of triazine herbicides in aqueous samples by dispersive liquid-liquid microextraction with gas chromatography-ion trap mass spectrometry," Journal of Chromatography A, vol. 1116, no. 12, pp. 89-97, 2007.

[5] N. Fattahi, Y. Assadi, M. R. M. Hosseini, and E. Z. Jahromi, "Determination of chlorophenols in water samples using simultaneous dispersive liquid-liquid microextraction and derivatization followed by gas chromatography-electroncapture detection," Journal of Chromatography A, vol. 1157, no. 1-2, pp. 23-29, 2007.

[6] A. Papadopoulou, I. P. Román, A. Canals, K. Tyrovola, and E. Psillakis, "Fast screening of perfluorooctanesulfonate in water using vortex-assisted liquid-liquid microextraction coupled to liquid chromatography-mass spectrometry," AnalyticaChimicaActa, vol. 691, no. 1-2, pp. 56-61, 2011.

[7] F. Pena-Pereira, N. Cabaleiro, I. Calle et al., "Directly suspended droplet microextraction in combination with microvolume UV-vis spectrophotometry for determination of phosphate," Talanta, vol. 85, no. 2, pp. 1100-1104, 2011.

[8] J. G. Huddleston, H. D. Willauer, R. P. Swatloski, A. E. Visser, and R. D. Rogers, "Room temperature ionic liquids as novel media for 'clean' liquid-liquid extraction," Chemical Communications, vol. 16, pp. 1765-1766, 1998.

[9] D. W. Armstrong, L. He, and Y. S. Liu, "Examination of ionic liquids and their Interaction with molecules, when used as stationary phases in gas chromatography," Analytical Chemistry, vol. 71, no. 17, pp. 3873-3876, 1999.

[10] J. G. Huddleston, A. E. Visser, W. M. Reichert, H. D. Willauer, G. A. Broker, and R. D. Rogers, "Characterization and comparison of hydrophilic and hydrophobic room temperature ionic liquids incorporating the imidazoliumcation," Green Chemistry, vol. 3, no. 4, pp. 156-164, 2001.

[11] C. F. Poole, "Chromatographic and spectroscopic methods for the determination of solvent properties of room temperature ionic liquids," Journal of Chromatography A, vol. 1037, no. 12, pp. 49-82, 2004.

[12] J. Liu, G. Jiang, Y. Chi, Y. Cai, Q. Zhou, and J. Hu, "use of ionic liquids for liquid-phase microextraction of polycyclic aromatic hydrocarbons," Analytical Chemistry, vol. 75, no. 21, pp. 5870-5876, 2003.

[13] E. Aguilera-Herrador, R. Lucena, S. Cárdenas, and M. Valcárcel, "Direct coupling of ionic liquid based singledrop microextraction and GC/MS," Analytical Chemistry, vol. 80, no. 3, pp. 793-800, 2008.

[14] Q. X. Zhou and C. L. Ye, "Ionic liquid for improved singledrop microextraction of aromatic amines in water samples," MicrochimicaActa, vol. 162, no. 1-2, pp. 153-159, 2008.

[15] J. F. Liu, Y. G. Chi, G. B. Jiang, C. Tai, J. F. Peng, and J. T. Hu, "Ionic liquid-based liquid-phase microextraction, a new sample enrichment procedure for liquid chromatography," Journal of Chromatography A, vol. 1026, no. 1-2, pp. 143-147, 2004.

[16] Y. C. Fan, Z. L. Hu, M. L. Chen, C. S. Tu, and Y. Zhu, "Ionic liquid based dispersive liquid-liquid microextraction of aromatic amines in water samples," Chinese Chemical Letters, vol. 19, no. 8, pp. 985-987, 2008.

[17] F. Q. Zhao, J. Li, and B. Z. Zeng, "Coupling of ionic liquidbased headspace single drop microextraction with GC for sensitive detection of phenols," Journal of Separation Science, vol. 31, no. 16-17, pp. 3045-3049, 2008.

[18] M. J. Trujillo-Rodríguez, P. Rocío-Bautista, V. Pino, and A. M. Afonso, "Ionic liquids in dispersive liquid-liquid microextraction," Trends in Analytical Chemistry, vol. 51, pp. 87-106, 2013.

[19] Ł. Marcinkowski, F. Pena-Pereira, A. Kloskowski, and J. Namieśnik, "Liquid-phase microextraction techniques based on ionic liquids for preconcentration and determination of metals," Trends in Analytical Chemistry, vol. 61, pp. 54-66, 2014.

[20] D. Ge and H. K. Lee, "Ionic liquid based hollow fiber supported liquid phase microextraction of ultraviolet filters," Journal of Chromatography A, vol. 1229, pp. 1-5, 2012.

[21] J. Zhang and H. K. Lee, "Headspace ionic liquid-based microdrop liquid-phase microextraction followed by microdrop thermal desorption-gas chromatographic analysis," Talanta, vol. 81, no. 1-2, pp. 537-542, 2010.

[22] M. T. Pena, M. C. Casais, M. C. Mejuto, and R. Cela, "Development of an ionic liquid based dispersive liquid-liquid microextraction method for the analysis of polycyclic aromatic hydrocarbons in water samples," Journal of Chromatography A, vol. 1216, no. 36, pp. 6356-6364, 2009.

[23] A. Sarafraz-Yazdi and F. Mofazzeli, "Ionic liquid-based submerged single drop microextraction: a new method for the determination of aromatic amines in environmental water samples," Chromatographia, vol. 72, no. 9-10, pp. 867-873, 2010.

[24] C. Yao, P. Twu, and J. L. Anderson, "Headspace single drop microextraction using micellar ionic liquid extraction solvents," Chromatographia, vol. 72, no. 5-6, pp. 393-402, 2010.

[25] M. Rezaee, Y. Assadi, M. R. M. Hosseini, E. Aghaee, F. Ahmadi, and S. Berijani, "Determination of organic compounds in water using dispersive liquid-liquid microextraction," Journal of Chromatography A, vol. 1116, no. 1-2, pp. 1-9, 2006.

[26] G. Shem and H. K. Lee, "Hollow fiber-protected liquid-phase microextraction of triazine herbicides," Analytical Chemistry, vol. 74, no. 3, pp. 648-654, 2002.

[27] J. L. Manzoori, M. Amjadi, and J. Abulhassani, "Ultra-trace determination of lead in water and food samples by using ionic liquid-based single drop microextraction-electrothermal atomic absorption spectrometry," AnalyticaChimicaActa, vol. 644, no. 1-2, pp. 48-52, 2009. 
[28] Ł. Marcinkowski, F. Pena-Pereira, A. Kloskowski, and J. Namiesnik, "Opportunities and shortcomings of ionic liquids in single-drop microextraction," Trends in Analytical Chemistry, vol. 72, pp. 153-168, 2015.

[29] M. H. Abraham, A. M. Zissimos, J. G. Huddleston, H. D. Willauer, R. D. Rogers, and W. E. Acree, "Ionic liquids: solvation ability and polarity," Industrial \& Engineering Chemistry Research, vol. 42, no. 3, pp. 413-418, 2003.

[30] X. Cao and Z. Le, "Synthesis of chiral ionic liquids," Chinese Journal of Organic Chemistry, vol. 2010, no. 30, pp. 816-832, 2010.

[31] X. J. Sun, C. Y. Wu, and J. Xing, "Ionic liquid-bonded polysiloxane as stationary phase for capillary gas chromatography," Journal of Separation Science, vol. 33, no. 20, pp. 3159-3167, 2010.

[32] X. J. Sun, Y. L. Zhu, P. Wang, J. Li, C. Y. Wu, and J. Xing, "High temperature and highly selective stationary phases of ionic liquid bonded polysiloxanes for gas chromatography," Journal of Chromatography A, vol. 1218, no. 6, pp. 833-841, 2011.

[33] S. Chun, S. V. Dzybua, and R. A. Bartsch, "Influence of structural variation in room-temperature ionic liquids on the selectivity and efficiency of competitive alkali metal salt extraction by a crown ether," Analytical Chemistry, vol. 73, no. 15, pp. 3737-3741, 2001.

[34] L. Pensado, E. Blanco, M. C. Casais et al., "Strategic sample composition in the screening of polycyclic aromatic hydrocarbons in drinking water samples using liquid chromatography with fluorimetric detection," Journal of Chromatography A, vol. 1056, no. 1-2, pp. 121-130, 2004.

[35] O. Delhomme, R. Rieb, and M. Millet, "Solid-phase extraction and LC with fluorescence detection for analysis of PAHsin rainwater," Chromatographia, vol. 65 , no. $3-4$, pp. 163-171, 2007.

[36] V. Fernandez, E. Concha, S. Muniategui, P. Lopez, and D. Prada, "Solid-phase microextraction-gas chromatographictandem mass spectrometric analysis of polycyclic aromatic hydrocarbons: towards the European Union water directive 2006/0129 EC," Journal of Chromatography A, vol. 1176, no. 1-2, pp. 48-56, 2007.

[37] M. H. Hosseini, M. Rezaee, S. Akbarian, F. Mizani, M. R. Pourjavid, and M. Arabieh, "Homogeneous liquidliquid microextraction via flotation assistance for rapid and efficient determination of polycyclic aromatic hydrocarbons in water samples," AnalyticaChimicaActa, vol. 762, pp. 54-60, 2013.

[38] J. L. Benedé, J. L. Anderson, and A. Chisvert, "Trace determination of volatile polycyclic aromatic hydrocarbons in natural waters by magnetic ionic liquid-based stir bar dispersive liquid microextraction," Talanta, vol. 176, pp. 253261, 2018.

[39] Q. Zhou and Y. Gao, "Determination of polycyclic aromatic hydrocarbons in water samples by temperature controlled ionic liquid dispersive liquid-liquid microextraction combined with high performance liquid chromatography," $A n$ alytical Methods, vol. 6, no. 8, pp. 2553-2559, 2014.

[40] J. Xiao, J. Cheng, F. Guo et al., "Ultrasound-assisted headspace ionic-liquid microextraction of polycyclic aromatic hydrocarbons at elevated temperatures," MicrochimicaActa, vol. 177, no. 3-4, pp. 465-471, 2012. 

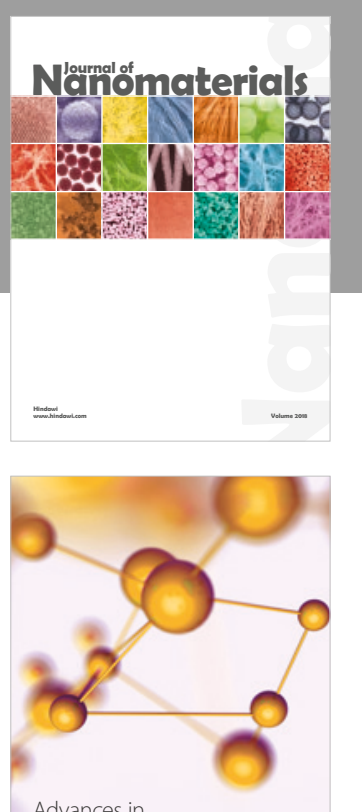

Physical Chemistry
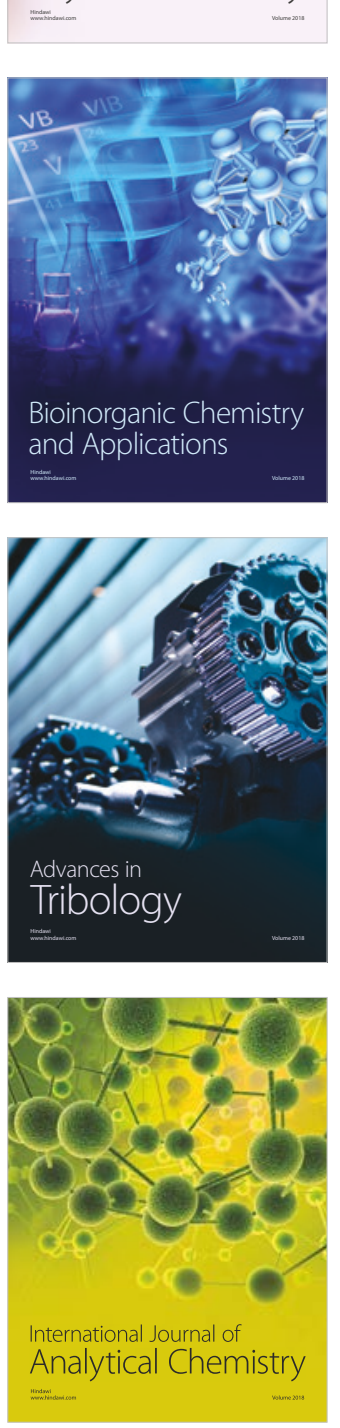

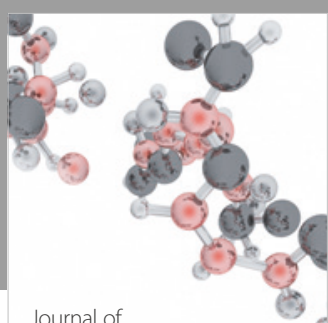

Analytical Methods

in Chemistry

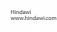

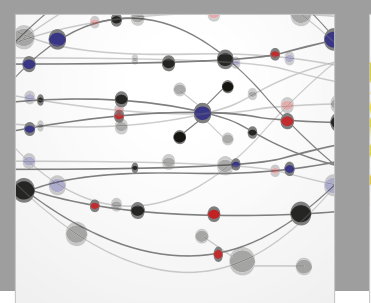

The Scientific World Journal

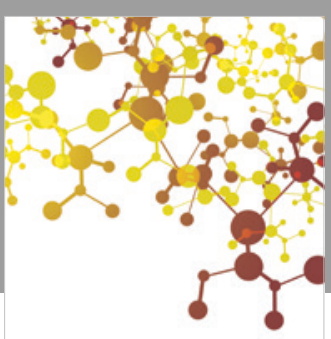

Journal of

Applied Chemistry
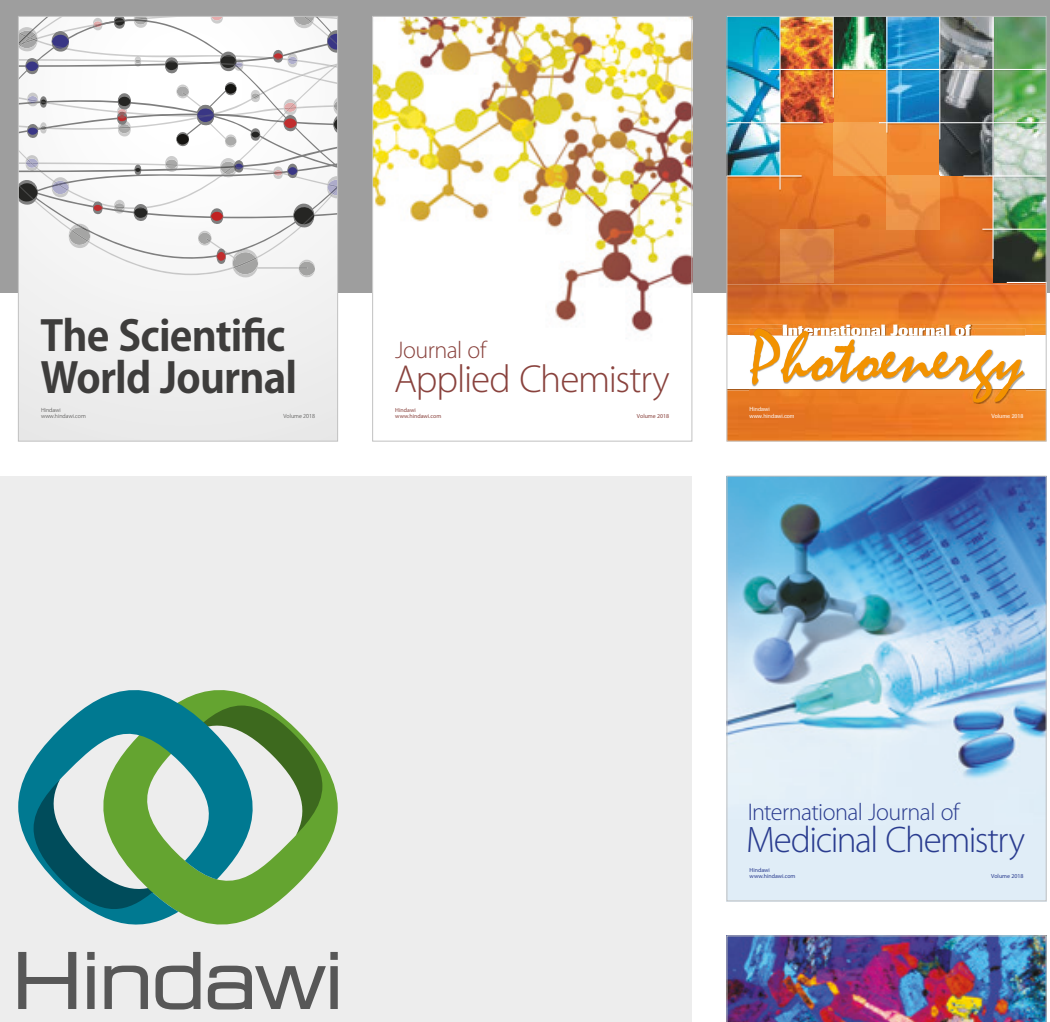

Submit your manuscripts at

www.hindawi.com
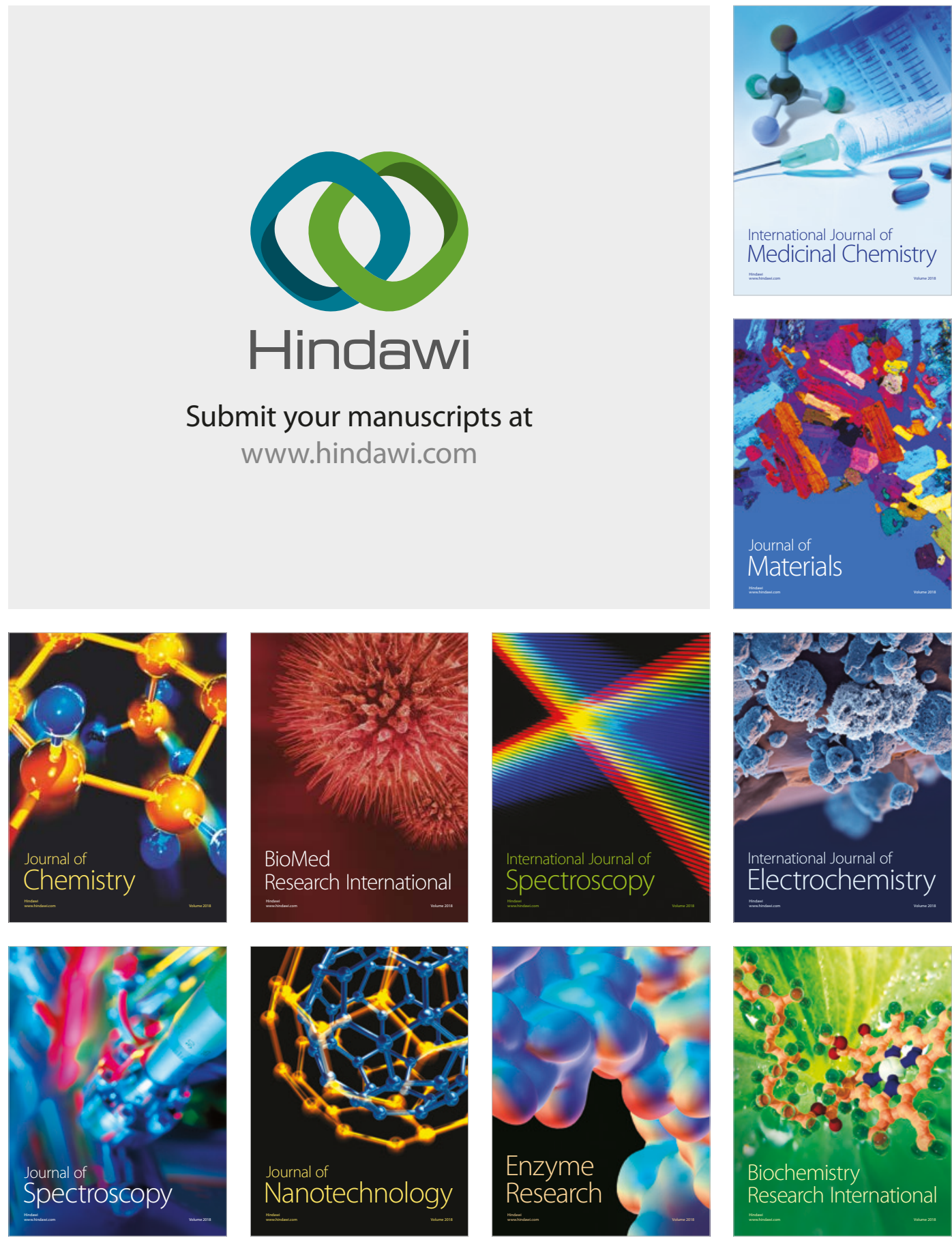
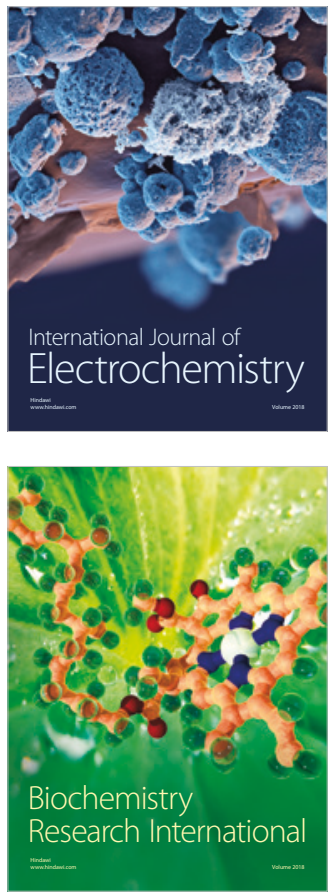